\author{
Deise Azevedo Longaray \\ Universidade Federal do Rio Grande - FURG, Rio Grande, RS, Brasil \\ Paula Regina Costa Ribeiro \\ Universidade Federal do Rio Grande - FURG, Rio Grande, RS, Brasil

\section{Travestis e transexuais: corpos (trans)formados e produção da feminilidade}

\begin{abstract}
Resumo: Neste artigo, discutimos a fabricação dos corpos de travestis e transexuais, problematizando os efeitos produzidos em seus processos de subjetivação. Para tanto, analisamos enunciações produzidas a partir da metodologia da História Oral Temática e da Observação Participante. No processo de constituição das travestilidades e transexualidades, investir na fabricação de um corpo feminino é uma forma de torná-lo visível e atrativo. A prostituição é destacada como uma experiência que produz efeitos na construção da feminilidade e da fabricação de si. A partir de técnicas de si, transexuais e travestis trazem à tona diferentes posições de sujeito, evidenciando outras possibilidades de viver os gêneros e as sexualidades, desafiando, em muitos casos, a heteronormatividade.
\end{abstract}

Palavras-chave: corpos; travestis; transexuais; feminilidade; (re)invenção de si.

\section{(c) (i)}

Esta obra está sob licença Creative Commons.

\section{Contextualizando o estudo}

[...] eu acho que discursos, na verdade, habitam corpos. [...] os corpos na verdade carregam discursos como parte de seu próprio sangue. E ninguém pode sobreviver sem, de alguma forma, ser carregado pelo discurso (BUTLER, apud PRINS E MEIJER, 2002).

A partir do entendimento de Judith Butler, exposto na epígrafe, de que os corpos são significados na linguagem e no discurso, e da emblemática frase de Simone de Beauvoir, de que "ninguém nasce mulher, torna-se mulher" (1967), o artigo tem como proposta discutir a fabricação dos corpos de travestis e transexuais, enfatizando os efeitos produzidos em seus processos de subjetivação ao construírem suas feminilidades. 


\begin{abstract}
1 Tese desenvolvida no âmbito do Programa de Pós-Graduação em Educação em Ciências da Universidade Federal de Rio Grande - FURG com o apoio da CAPES e do CNPq. Na pesquisa investigamos os enunciados e as práticas de si que constituem os sujeitos gays, travestis e transexuais nos espaços educativos.

${ }^{2}$ Naraya Luísa Brum se autoidentifica como transexual. Nasceu em 29 de julho de 1987. É solteira. Estuda na UNOPAR, cursando Serviço Social. Maria Regina se autoidentifica como transexual. Nasceu em 4 de agosto de 1979 É casada e trabalha como cabeleireira. Gisele se autoidentifica como transexual. Nasceu em 25 de fevereiro de 1988. É solteira e trabalha como cabeleireira. Cindy se autoidentifica como travesti. Nasceu em 3 de março de 1986 trabalha como cabeleireira e é solteira. Luciana Guerra se autoidentifica como transexual lésbica. Nasceu em 28 de março de 1981, é solteira, porém tem uma namorada. É proprietária de uma lan house.
\end{abstract}

Esse trabalho compreende o quarto movimento de uma pesquisa de doutorado, ' no qual analisamos enunciações produzidas por transexuais e uma travesti, ${ }^{2}$ problematizando o enunciado, a produção do corpo e a (re)invenção de si.

A partir de uma perspectiva foucaultiana, para que um enunciado torne-se visível, é preciso atentar-se, primeiramente, para as enunciações que o compõem. Entendemos que "diferentes enunciações podem ser repetições de um enunciado idêntico" (Hubert DREYFUS; Paul RABINOW, 2010, p. 58). Entendemos as narrativas analisadas neste estudo como enunciações que sustentam e dão visibilidade ao enunciado destacado. Os enunciados visibilizam e sustentam um discurso; neste caso, o discurso da feminilidade.

Entendemos o discurso como um conjunto de enunciados que podem ser de campos diferentes, mas que fazem parte do mesmo sistema de formação, o qual reúne vários discursos a partir de regras que os agregam e os relacionam. Os discursos não são entendidos "como conjuntos de signos (elementos significantes que remetem a conteúdos ou representações), mas como práticas que formam sistematicamente os objetos de que falam" (Michel FOUCAULT, 2005, p. 55).

Com o propósito de evidenciar o enunciado destacado, analisamos enunciações produzidas a partir da metodologia da História Oral Temática, por meio de entrevistas baseadas na constituição das subjetividades das participantes, e da Observação Participante, realizada em um salão de beleza, onde as participantes transitavam, e durante reuniões da Associação LGBT do município de Rio Grande.

A História Oral Temática é utilizada quando o projeto de pesquisa refere-se a um assunto, tema, etapa ou acontecimento específico da vida do/a entrevistado/a; neste estudo, a constituição dos sujeitos enquanto gays, travestis e transexuais. Realizamos entrevistas temáticas que "versam prioritariamente sobre a participação do entrevistado no tema escolhido" (Verena ALBERTI, 2005, p. 37). Articulada a essa metodologia, trabalhamos com a Observação Participante, que é caracterizada pela presença do pesquisador/a no campo; o/a observador/a é parte ativa do processo. Ela é entendida como um processo, em que o/a pesquisador/a deve tornar-se realmente um participante do método, obtendo, dessa forma, acesso ao campo de estudos em que vai atuar e aos sujeitos que pretende observar, atendendo, assim, aos objetivos da pesquisa a ser desenvolvida (Heraldo VIANNA, 2007).

Para o processo analítico, discutimos sobre algumas enunciações das entrevistadas e sobre trechos de diários produzidos ao longo da Observação Participante, com o propósito de problematizar acerca do processo de

762 Estudos Feministas, Florianópolis, 24(3): 761-784, setembro-dezembro/2016 
construção da feminilidade nos corpos de quatro transexuais e de uma travesti, apresentando a constituição de modos singulares de ser e estar na sociedade.

É no corpo que as marcas das experiências vivenciadas, as modificações e (trans)formações realizadas por travestis e transexuais são evidenciadas, possibilitando a emergência de outros modos de existencialização (Wiliam PERES, 2011). É sobre os corpos que são inscritos os marcadores subjetivos, entre eles os de gênero; e as marcas que se inscrevem nos corpos são vistas e entendidas de diferentes formas, dependendo do contexto histórico e cultural vivenciado pelos sujeitos.

Nomeados e classificados no interior de uma cultura, os corpos se fazem históricos e situados. Os corpos são "datados", ganham um valor que é sempre transitório e circunstancial. A significação que se lhes atribui é arbitrária, relacional e é, também, disputada. Para construir a materialidade dos corpos e, assim, garantir legitimidade aos sujeitos, normas regulatórias de gênero e sexualidade precisam ser continuamente reiteradas e refeitas. Essas normas, como quaisquer outras, são invenções sociais. Sendo assim, como acontece com quaisquer outras normas, alguns sujeitos as repetem e reafirmam e outros delas buscam escapar (Guacira LOURO, 2004, p. 89).

Partindo desse pressuposto, as travestis e transexuais, de algum modo, ao (re)inventarem seus corpos, buscam escapar das convenções impostas ao seu sexo/gênero. Em contrapartida, ao reproduzirem alguns aspectos da feminilidade, acabam naturalizando determinados comportamentos e posturas. Elas produzem atos performativos e subversivos ao mesmo tempo. No entanto, outras formas de viver a feminilidade são apresentadas.

Esses outros modos de existencialização, exibidos pelas travestis e transexuais, tornam-se, portanto, alvo de investigação e análise. O gênero, assim, caracteriza-se como uma categoria diagnóstica (Berenice BENTO; Larissa PELÚCIO, 2012).

De acordo com a $5^{a}$ versão do Manual de Diagnóstico e Estatísticas de Distúrbios Mentais (DSM-V), publicado em maio de 2013, a transexualidade não é mais considerada uma doença mental, um transtorno de identidade de gênero como era descrita na versão anterior do documento. Contudo, permanece, no código, a categoria disforia de gênero, referindo-se aos problemas que a pessoa transexual tem ou pode vir a ter por não se identificar com o corpo e a genitália de nascimento.

Discursos produzidos sobre a sexualidade e sobre os gêneros, no âmbito da Medicina, da Psiquiatria, da Psicologia, 
entre outros campos do saber, e que proliferam ainda hoje na sociedade, buscam, de certa forma, esquadrinhar os sujeitos e normalizar as atitudes e práticas de gays, lésbicas, bissexuais, travestis e transexuais, que são "classificados/ as" como doentes, anormais e desviantes. Sobre esses/as, aplicam-se estratégias de normalização, tais como a produção de saberes, de modo a classificá-los/as; a investigação sobre seus corpos e suas práticas; o controle e a vigilância, entre outras. A partir do século XIX, por intermédio da Psiquiatria, a Medicina apresenta sua função social em uma sociedade da normalização. O poder da Medicina emerge em diversos contextos: na família, nas escolas, nos tribunais; avança, também, sobre a sexualidade, sobre a educação etc. Nesse sentido, "a norma se torna o critério de divisão dos indivíduos. Dado o fato de estar sendo constituída uma sociedade da norma, a medicina como a ciência acima de tudo do normal e do patológico, será a ciência rainha" (FOUCAULT, 2011 , p. 395). Para Foucault (2010), é a partir do século XVIII que a Medicina instaura-se no cenário da loucura, por meio do estudo das curas das doenças nervosas. Nesse contexto, possibilita-se a emergência da psiquiatria da observação e instaura-se um diálogo entre o louco e o médico. Estabelecem-se algumas ideias terapêuticas acerca da cura da loucura. Entretanto, na era clássica, não há distinção entre medicamentos físicos, psicológicos ou morais, uma vez que a Psicologia não existe. Isso só ocorrerá no século XIX, quando são inventados os métodos morais. "A distinção entre o físico e o moral só se tornou um conceito prático na medicina do espírito no momento em que a problemática da loucura se deslocou para uma interrogação do sujeito responsável" (FOUCAULT, 2010, p. 325).

Kleber Prado Filho e Sabrina Trisotto (2015) discorrem sobre a Psicologia entendendo-a como disciplina da norma. Para eles, a Psicologia tem o poder de dizer quem são os sujeitos, de falar de nossa subjetividade, "no entanto, ela sempre nos enuncia como sujeitos da norma, remetidos a ela, comparativamente a outros sujeitos como nós, marcando e nomeando os desvios em termos de médias, curvas, condutas adequadas ou não, sancionadas ou não, quando não patologizadas." Segundo Foucault, a Psicologia contemporânea pode ser caracterizada pela investigação e análise do anormal (2002).

As transexuais e as travestis são alvos dessa investigação por serem entendidas como corpos abjetos, sendo, para muitos/as, consideradas aberrações, pois desafiam a heteronormatividade, ou seja, são produzidos fora da inteligibilidade social, incoerentemente em relação às normas hegemônicas. Provocam, muitas vezes, repulsa na sociedade.

764 Estudos Feministas, Florianópolis, 24(3): 761-784, setembro-dezembro/2016 
[...] O abjeto designa aqui precisamente aquelas zonas "inóspitas" e "inabitáveis" da vida social, que são, não obstante, densamente povoadas por aqueles que não gozam do status de sujeito, mas cujo habitar sob o signo do "inabitável" é necessário para que o domínio do sujeito seja circunscrito (BUTLER, 2007, p. 155).

Embora transexuais e travestis sejam relacionadas à abjeção e tenham, nesse sentido, sofrido com atos de repúdio, com distintas formas de preconceito - nos diferentes âmbitos e instâncias sociais -, elas têm travado lutas diárias pela visibilidade e pelo respeito, pelo reconhecimento enquanto sujeitos de direitos. Dessa forma, "de um corpo despotencializado e fraco surge um corpo empoderado e forte, guerreiro e reivindicador de direitos" (PERES, 2013). Muitas/os travestis e transexuais lutam pela promoção de políticas públicas que as/os defendam; buscam desconstruir o processo de patologização com relação à transexualidade e os discursos que as associam à doença, ao pecado etc, resistindo aos processos de hierarquização e normalização.

A fim de discutir e problematizar os processos de subjetivação das participantes da pesquisa, apresentamos as enunciações - falas e trechos dos diários - e as análises sobre elas produzidas.

\section{Transexualidades e travestilidades: reconhecer-se...}

Os termos transexualidades e travestilidades são polissêmicos, (res)significados pelos sujeitos, dependendo do contexto e das experiências vivenciadas, evidenciando que múltiplos são os modos de ser travesti e transexual. Os entendimentos acerca das transexualidades e travestilidades são imbricados às diferentes e singulares maneiras de viver de cada sujeito e, por isso, são entendidos de distintas formas.

As entrevistadas relataram sobre como se identificavam e quais seus entendimentos acerca da transexualidade e da travestilidade.

[...] A transexualidade é atribuída à tua identificação com o gênero oposto ao que designaria a tua genitália. Por exemplo, eu tenho pênis, o que isso, no caso, implicaria? Que eu tivesse um gênero masculino. Então, tu não teres o gênero masculino, isso é a tua transexualidade, é tu assumir um gênero diferente do que seria condizente com a tua genitália. [...] travestilidade é quando tu não tens a tua identidade definida como mulher ou homem, ou como feminino ou masculino. Quando a pessoa é travesti, ela não tem o gênero feminino somente. Ela está entre os dois 
gêneros [...]. Isso é complicado, porque a gente tem na nossa cabeça que só pode ser homem ou mulher. Que só pode ser feminino ou masculino (Luciana Guerra).

[...] É que, hoje em dia, a operada não é mais transexual, é operada. Entendesse? As travestis que se montam $24 \mathrm{~h}$ por dia, que são as transex que têm silicone na bunda, entendesse? E as travestis que se montam, parece que agora modificou, está totalmente diferente. [...] Então, hoje em dia, a gente diz que operada é operada, não é transex. As travestis são as que estão se montando de mulher (Naraya).

Eu me reconheço como transexual, porque travesti, pra mim, é o que eu já vivi, me vestia de mulher de noite e no outro dia era um menino que passava como um menino normal. Eu me travestia. Hoje, é o meu dia a dia, é minha vida, eu tenho uma vida como tu tens. Sou casada há seis anos, a gente vive junto. Então, eu tenho meu dia a dia como mulher. Dona de casa, tenho que cozinhar, tenho que lavar, tenho que passar, todas as atividades ruins. E eu sou casada com um homem hetero. Ele sempre me diz que me enxerga como mulher, entendeu? Eu me trato como mulher, eu compro calcinha, eu compro calça feminina, eu vou no vestiário feminino, quando eu vou ao toalete eu vou ao toalete feminino. Eu vou fazer xixi, eu nunca faço de pé. Mas não é uma coisa que seja forçada minha, já é natural, sabe? (Maria Regina).

Travesti é aquela que se veste, às vezes se traveste de mulher, no caso, mas nem sempre. É uma pessoa que se traveste de mulher. Transexual é aquela que vive dia e noite de mulher, tem silicone também, mas é transexual. Porque isso é da cabeça, entendeu? Se tu tem na tua cabeça que tu és uma mulher, que tu queres ser feminina, que tu é 24 horas mulher, tu é transexual. Não precisa ser necessariamente operada. Eu me entendi como transexual mesmo, depois que eu coloquei silicone na bunda, que eu disse: - Deu, não tem mais volta! Estou com um corpo de mulher, eu sou mulher. [...] No sexo, a travesti geralmente curte ser ativa e passiva, a transexual ela só é passiva. [...] Tem muitas travestis que são siliconadas, se acham transexuais, mas não são transexuais porque não têm a cabeça de transex. [...] A transexual não gosta de usar o órgão masculino dela no caso. Se eu estou namorando ou ficando com alguém, eu não vou ser ativa. Eu vou ser passiva. Eu não rejeito a minha genitália, não tenho problema nenhum, mas eu não gosto de ser ativa. Isso que é ser transexual (Gisele).

As enunciações distinguem o que é ser travesti e transexual; também evidenciam entendimentos próprios de cada uma das participantes. As entrevistadas destacam

766 Estudos Feministas, Florianópolis, 24(3): 761-784, setembro-dezembro/2016 
como se identificam, apresentam e explicam cada um dos termos a partir de seus entendimentos e vivências, apontam outras nomenclaturas como, por exemplo, "operada".

Algumas questões são apontadas nessas enunciações: 1) a diferenciação entre travestilidade e transexualidade; 2) a naturalização do que pertence ao universo feminino e 3) a rejeição ou não à genitália e a relação com a transexualidade.

Com relação às diferenças apontadas entre a travestilidade e transexualidade, Luciana Guerra destaca que travestis vivem o masculino e o feminino ao mesmo tempo, o que, segundo ela, é confuso para muitas pessoas, pois essa possibilidade de transitar entre os dois gêneros escapa aos regimes de verdade instituídos socialmente, ou seja, as convenções que produzem e reafirmam a heteronormatividade e instituem modos de ser, ou se é mulher, e se pertence ao universo feminino, ou se é homem e se pertence ao universo masculino. As travestis rompem as fronteiras de gêneros, desconstroem as normatividades, instituindo outros modos de subjetivação.

Segundo Márcio da Fonseca (2003), os processos de subjetivação passam a constituir os indivíduos como sujeitos. É a partir deles que os sujeitos passam a se constituir como sujeitos de uma sexualidade; que os sujeitos buscam o conhecimento de si, voltam-se a si, decifram-se. A subjetividade refere-se à "maneira pela qual o sujeito faz a experiência de si mesmo em um jogo de verdade, no qual ele se relaciona consigo mesmo" (FOUCAULT, 2010a, p. 236). É nesse jogo de relação consigo e, também, com os/as outros/as, que os sujeitos, a partir de discursos e jogos de verdade, reconhecemse como sujeitos de uma sexualidade.

Peres $(2009 ; 2011)$ discute sobre a subjetividade, diferenciando os processos de subjetivação normatizadores dos singularizadores. Os normatizadores buscam, de alguma forma, manter a norma estabelecida socialmente. Já os singularizadores "se mostrariam como linhas de fuga, contrapoderes ou resistências frente ao poder que facilitariam a expressão da diferença, da singularidade e de modos desejantes potentes e criativos" (2011). A partir dos modos de subjetivação singularizadores, os sujeitos rompem com a norma, tornam-se resistentes a ela. Ao refletirmos sobre a constituição de gays, travestis e transexuais, entendemos que, ora percebemos os processos normatizadores operando, ora os singularizadores. Em alguns momentos, embora tais sujeitos busquem borrar as fronteiras, romper com a "norma heterossexual" e com o processo dicotômico homem/mulher, masculino/feminino, é possível evidenciarmos, a partir de suas posições de sujeito, a permanência e fixação desses binarismos e de modelos hegemônicos. 
Outro ponto de destaque nas narrativas é a diferenciação estabelecida entre a travestilidade e a transexualidade. A travestilidade é um processo contínuo de produção de subjetividade marcado pela construção constante, pelo nomadismo, pela transitoriedade; enfim, pela descontinuidade e pelo enfrentamento às categorias e normas estabelecidas (PELÚCIO, 2013; PERES, 2012).

A experiência transexual é produzida e definida a partir da demarcação da travestilidade. Essa diferenciação estabelecida entre uma e outra, muitas vezes, aloca a transexualidade em uma posição de superioridade, conferindo um caráter de legitimidade, atribuindo à travestilidade uma categoria identitária inferior (BENTO, 2008).

Ao fazerem uma distinção entre travestis e transexuais, enunciações apontam a questão do "sentir-se e ser mulher" relacionada à transexualidade. Estabelecer uma diferença entre a travestilidade e a transexualidade, baseando-se no fato de a transexual "sentir-se mulher", é uma forma de naturalizar a categoria mulher, destacando atributos ou características pertencentes a todas as mulheres (BENTO, 2008). Isso pode ser evidenciado na fala de Maria Regina, quando relaciona o "ser mulher" e "pertencer ao universo feminino" com a realização de atividades domésticas diárias (cozinhar, lavar, passar), que, segundo ela, são desagradáveis.

Com relação a essa distinção, Gisele destaca que as transexuais são passivas durante a relação sexual, mesmo que não rejeitem a genitália, no sentido de optarem pela cirurgia de mudança de sexo. Diferentemente das travestis, as transexuais não usam o pênis para a penetração, o que representa, segundo Gisele, ter a "cabeça de transex" e "gostar de ser mulher". Nesse sentido, a penetração parece ser um fator determinante para explicar e definir a travestilidade (Don KULICK, 2008). Entretanto, as duas subjetividades - travestilidade e transexualidade - são experiências atreladas ao gênero e "representam respostas aos conflitos gerados por uma ordem dicotomizada e naturalizada para os gêneros" (BENTO, 2008, p. 55).

Outro aspecto evidenciado nas enunciações é a discordância com a genitália e, consequentemente, o processo de mudança de sexo, característica atribuída à experiência transexual. Gisele destaca que não "rejeita" sua genitália, entretanto, admite que não gosta de "ser ativa", afirmando que isso "é que é ser transexual". Tal afirmação contrasta com a enunciação, a seguir, de Luciana Guerra, que diz não ter problemas com relação à sua genitália e "fazer uso" desta para, então, sentir prazer. Partindo desse pressuposto, as entrevistadas comentaram sobre a cirurgia de mudança de sexo:

768 Estudos Feministas, Florianópolis, 24(3): 761-784, setembro-dezembro/2016 
Não fiz e não pretendo fazer, porque é uma cirurgia muito invasiva, muito agressiva. Tem um pós-operatório que é eterno. Enquanto fores viva, tens que lubrificar, porque a neovagina não produz lubrificação sozinha. [...] Muitas têm a imagem de que, quando fizerem a cirurgia, elas vão ser aceitas socialmente como mulheres. [...] mas a genitália não é uma coisa que aparece socialmente. Muitas rejeitam por causa disso, porque acham que aquilo ali é o fator excludente dela na sociedade. Então, algumas têm esse entendimento. Talvez não tivessem, se fossem aceitas socialmente como mulheres. [...] Pra tu teres um prazer sexual, tu tens que ter um contato físico com a tua genitália. Então, se eu não aceitar a minha genitália e não tiver um contato físico com ela e achar que é errado ter prazer com ela do jeito que eu tenho, ou eu faço a cirurgia ou durante todo esse tempo que eu espero pra fazer a cirurgia eu fico sem fazer sexo [...]. Eu uso a minha genitália, porque não bate arrependimento. Eu acho que a questão da identidade de gênero não pode estar relacionada com a questão de tu teres pênis ou vagina (Luciana Guerra).

Não. Porque não vou querer perder todo o meu prazer (Naraya).

[...] eu não penso em mudar de sexo (Gisele).

Luciana Guerra aponta que, além de "usar" a genitália para sentir prazer, assim como comenta Naraya, a cirurgia não garante que as transexuais sejam aceitas como mulheres, pois a genitália não é visível socialmente. A enunciação de Luciana traz à tona a discussão de que ser mulher e ser homem vai além da questão da genitália, ou seja, de ter uma vulva ou um pênis.

Se o gênero são os significados culturais assumidos pelo corpo sexuado, não se pode dizer que ele decorra de um sexo desta ou daquela maneira. Levada a seu limite lógico, a distinção sexo/gênero sugere uma descontinuidade radical entre corpos sexuados e gêneros culturalmente construídos. Supondo por um momento a estabilidade do sexo binário, não decorre daí que a construção de 'homens' aplique-se exclusivamente a corpos masculinos, ou que o termo 'mulheres' interprete somente corpos femininos. [...] Quando o status construído do gênero é teorizado como radicalmente independente do sexo, o próprio gênero se torna um artifício flutuante, com a consequência de que homem e masculino podem, com igual facilidade, significar tanto um corpo feminino como um masculino e mulher e feminino, tanto um corpo masculino como um feminino (BUTLER, 2010, p. 24 [grifos da autora]). 
Ao discutir sobre a não distinção entre sexo e gênero e ao afirmar que "talvez o sexo tenha sempre sido gênero", Butler não está negando a existência de uma materialidade, de um corpo. Ela propõe pensarmos acerca dos efeitos ou da materialização produzida por práticas regulatórias sobre o sexo. Isto é, há um sexo, um corpo carne, mas essa materialidade é constituída e produzida pelos discursos sociais, culturais e históricos. Discursos esses que buscam estabelecer uma ordem compulsória ou uma coerência entre sexo, gênero, desejo e prática sexual (BUTLER, 2010; Sara SALIH, 2012). Butler destaca que "o sexo se torna compreensível por meio dos signos que indicam como ele deveria ser lido e compreendido. Esses indicadores corporais são os meios culturais através dos quais o corpo sexuado é lido" (2013). Segundo a autora, o corpo sexuado é construído a partir de signos produzidos sobre ele e não há como destacarmos o que é material e o que é cultura nessa construção (BUTLER, 2013).

A partir de Butler, o gênero é entendido como "ato", como "ação", e não atribuição natural do corpo.

Esses atos, gestos e atuações, entendidos em termos gerais, são performativos, no sentido de que a essência ou identidade que, por outro lado, pretendem expressar, são fabricações manufaturadas e sustentadas por signos corpóreos e outros meios discursivos (BUTLER, 2010, p. 194).

O gênero é construído a partir de atos repetidos. Ele constitui-se a partir de um conjunto de normas mantidas e repetidas, que se instituem sobre os corpos, tornando-o "substância" visível, aparente. O gênero, portanto, é performativo. O que significa que se produz uma série de efeitos. Assim como o sexo, o gênero é produzido e reproduzido a todo tempo. Nenhum sujeito pertence a um gênero desde sempre. O gênero é produzido culturalmente, mas ele é, também, um "domínio de agência ou de liberdade".

Partindo desse pressuposto, sexo e gênero são discursivamente construídos, isto é, não há uma naturalidade no sexo. Há inúmeras interpretações e normas de gênero que se instauram e são transmitidas aos nossos corpos; cabe ao sujeito assumir/seguir ou não tais normas. Há uma diferença em ser e existir o próprio corpo. Existir o próprio corpo possibilita uma escolha, ou seja, há, também, a possibilidade de "rejeição" (SALIH, 2012). Podemos pensar o processo de produção dos corpos de transexuais e travestis, que constroem e alteram o corpo com o qual nascem, isto é,

[...] o corpo é um texto socialmente construído, um arquivo vivo na história do processo de (re)produção 
sexual. Neste processo, certos códigos naturalizamse, outros, são ofuscados e/ou sistematicamente eliminados, postos às margens do humanamente aceitável, como acontece com as pessoas transexuais (BENTO, 2008, p. 30).

A própria cirurgia de mudança de sexo, desejo de muitas transexuais, é uma forma de dar existência a si própria, uma forma de reconhecimento e "completude" na produção da subjetividade transexual. Maria Regina discute o ser mulher, associando-o à cirurgia. Na época da realização de sua entrevista, Maria Regina estava participando do processo transexualizador; no entanto, teve que interromper porque começou a trabalhar novamente, o que dificultou suas idas e vindas até a cidade onde realizava o processo.

É assim: não muda em nada, tu só tens que provar para os psicólogos, psicanalistas e várias pessoas que estão ali, que tu não vais te arrepender, que isso é bem resolvido na tua vida, sabe? [...] isso é bem resolvido pra mim. Eu sempre digo que eu só uso pra fazer xixi. Vamos supor, eu acredito que eu sou, eu e o geral, travestis e transexuais, é uma evolução. Tipo assim, antes de eu ser travesti, eu fui gay. Aí, depois de ser travesti, o travesti me preparou para eu ser um transexual e, antes da operação, eu estou me preparando para o meu pós, porque eu não vou mais me considerar um transexual, porque isso aí pra mim é uma palhaçada. Porque se tu vai te operar, eu vou ser uma mulher. [...] Então, isso eu acho que faz parte da feminilidade. Acho que é da mulher, é coisa de mulher mesmo. Quando eu era criança, eu me lembro que pensava: - Por que eu nasci homem? Eu chorava porque eu tinha nascido homem, não gostava de ter nascido homem.

Maria Regina destaca que o "se tornar transexual" é um processo acompanhado por "vozes autorizadas", isto é, de especialistas da área médica e psicológica, que irão diagnosticar e caracterizar a transexualidade ou não. Além disso, ela entende a transexualidade como um processo evolutivo. Com se fosse uma pré-condição primeiramente reconhecer-se como gay, depois como travesti e, logo, como transexual, estabelecendo uma correspondência e relação entre a identidade sexual e a identidade de gênero. Entretanto, ser gay refere-se à homossexualidade, ou seja, à identidade sexual de um sujeito; ser transexual refere-se ao modo de como viver a masculinidade ou a feminilidade. A pessoa pode ser transexual e heterossexual, ou, também, transexual e homossexual ou bissexual. Luciana Guerra, por exemplo, se autoidentifica como transexual lésbica, pois se 
entende como uma mulher pertencente ao gênero feminino e relaciona-se afetiva e sexualmente com outras mulheres.

Ao destacar a transexualidade como "uma evolução", Maria Regina acaba instituindo um único modo de reconhecer-se enquanto transexual.

Não existe uma "identidade transexual", mas posições de identidades organizadas através de uma complexa rede de identificações que se efetiva mediante movimentos de negação e afirmação de modelos disponibilizados socialmente para se definir o que seja um/a homem/mulher de "verdade" (BENTO, 2006, p. 201).

Maria Regina destaca que, após a cirurgia, ela não se identificará como transexual, mas como mulher, pois "não terá mais" o qualificador do masculino, o pênis. Em uma conversa durante o processo de observação participante, afirma o quanto é importante a realização da cirurgia de mudança de sexo.

Comentei com Maria Regina que havia lido um artigo sobre travestilidade e transexualidade e que muitas transexuais comentavam que a cirurgia de mudança de sexo era uma forma de liberdade. [...] perguntei à Maria Regina se ela iria fazer a sua cirurgia de mudança de sexo. Ela disse que após a colocação do silicone, com certeza fará a mudança de sexo, que a colocação da prótese mamária era o primeiro passo. E que assim como disseram as transexuais do artigo que li, a cirurgia de mudança de sexo seria, sim, uma forma de sentir-se livre, já que ela não "usa" o pênis na relação sexual e se sentiria melhor sem ele [EXCERTO DIÁRIO de CAMPO, 28/05/2013].

Para ela, a realização da cirurgia de mudança de sexo é uma forma de reconhecimento de um corpo que, até então, é incoerente com sua subjetividade. Ao longo de um processo de fabricação desse corpo, Maria Regina vai moldando-o de forma, então, a reconhecê-lo como seu, instituindo, ao seu modo, normas no seu corpo que ora são reiteradas, ora são recompostas. É a partir do seu corpo que ela se afirma, reconhece-se enquanto sujeito.

\section{Transexualidades e travestilidades: feminilizar-se...}

No processo de construção subjetiva da transexualidade e travestilidade, investir na fabricação de um corpo, tornando-o visível, porém atrativo, é também uma maneira de produção de uma imagem dita normal, ou seja, coerente com as posturas adotadas diariamente. É sobre esse processo de modelagem corporal que as enunciações a seguir tratam.

772 Estudos Feministas, Florianópolis, 24(3): 761-784, setembro-dezembro/2016 
Eu queria mudar meu corpo desde uns dez anos de idade. Então, eu comecei a conhecer hormônios, sabendo de outros casos de transexuais que já tomavam hormônios e qual hormônio que tomavam, se tinha efeito colateral ou não. Aí eu comecei o tratamento hormonal, mas isso foi só com 22 anos; mas eu já tinha o cabelo comprido [...]. Eu obtinha todas as informações pela internet, por casos de outras transexuais que estavam tomando o mesmo hormônio e também por alguns relatos de endocrinologistas que elas consultavam (Luciana Guerra).

[...] eles te dão muitos hormônios. Estrogênios conjugados, vários tipos de hormônios para matar todos os hormônios masculinos que têm no corpo, pra ele sair. [...] a gente vai baixando a cota de hormônios masculinos e aumentando a de feminino. $E$ aí isso faz com que os pelos caiam (Maria Regina).

[...] quando eu estava vestida de mulher, eu comecei a ver que era diferente, eu vi que os homens olhavam mais, que as pessoas achavam mais bonita. Na verdade, eu sempre quis. Só que eu tinha medo, entendeu? Medo do preconceito ser maior, na verdade. Aí eu comecei a me vestir de mulher aos poucos, fui saindo. Até que um dia eu me olhei no espelho e falei: - Não, não dá mais. Eu quero ser mulher, eu vou ser mulher. E foi onde eu comecei, deixei o cabelo crescer, coloquei mega-hair. Comecei a tomar hormônios, me vesti de mulher, até que eu coloquei silicone na bunda. [...] Melhorou muita coisa para mim no aspecto amoroso. Na vida... agora eu não tenho problema com nada, sabe? Parece que eu me libertei. Muito tempo eu não fui feliz por causa disso. [...] O silicone ajudou um monte. Qualquer roupa feminina, vou ficar com um corpo feminino (Gisele).

Destaca-se, ao longo dessas narrativas, que a pretensão de mudar o corpo é procedida pelo processo de ingestão de hormônios. A farmacologia é tida como o suporte da fabricação do corpo de travestis e transexuais. Esse processo de investimento na mudança corporal e na feminilização desse corpo é sustentado por discursos produzidos por especialistas da área da endocrinologia. Assim, não é qualquer sujeito que concede uma "consulta" em relação ao uso de hormônios, mas, sim, aquele ao qual Ihe foi atribuído um direito privilegiado ou exclusivo da fala (FOUCAULT, 2009).

É interessante considerar que Luciana Guerra conhecia pela Internet histórias de pessoas que já investiram nesse processo de transformação corporal e, com isso, obteve maiores informações sobre o mesmo, bem como uma forma de construção de si a partir da narrativa do/a outro/a. Para Christine Delory-Momberger, a narrativa do outro 


\begin{abstract}
${ }^{3}$ A partir da perspectiva teórica assumida, operamos com o termo criatividade, entendendo-o não como algo dado, que nasce com o sujeito, mas que o constitui ao longo de toda vida a partir de práticas, instâncias e discursos. Se criamos e recriamos nossa história ao longo de toda nossa existência, podemos afirmar que criamos coisas a todo momento a partir de nossas vivências.
\end{abstract}

[...] é assim um dos lugares onde experimentamos nossa própria construção biográfica; onde ela pode deslocar-se, reconfigurar-se, alargar seu horizonte; onde ela se põe à prova como escrita de si. A narrativa do outro é, de certo modo, um laboratório das operações de biografização que realizamos sobre nossa própria vida, nas condições de nossas inscrições sócio-históricas e de nossos pertencimentos culturais (2008, p. 62).

É a partir da experiência biográfica do/a outro/a que podemos nos (re)inventar, constituir-nos e escrever a nossa própria história. Esse processo de construção e (re)invenção de si é produzido por intermédio de práticas de liberdade.

Ainda que exista o preconceito, a invenção de si sinaliza níveis de liberdade. Sem o mínimo de liberdade de invenção, não há uma sexualidade e, se bem entendida, uma humanidade. A ausência de liberdade impede o movimento de busca pela completude que a sexualidade, como dimensão da humanidade, eternamente persegue com a experiência. [...] Em outras palavras, existe um nexo entre a sexualidade, o prazer da experiência e a curiosidade pelo saber. Esse movimento infinito em busca da completude e em busca do conhecimento (subversivo, porque criativo), eu chamo [...] de desejo criativo (Marcio CAETANO, 2011, p. 124-125).

Nesse processo de produção do eu, os sujeitos colocam em evidência sua criatividade ${ }^{3}$ a partir do momento em que conhecem o que desejam vivenciar; constroem, nesse sentido, sua imagem a partir de práticas de liberdade utilizadas na (re)invenção do seu corpo e na reconstrução de sua própria vida. As práticas de liberdade consistem em maneiras ou em formas que damos à subjetividade. A liberdade refere-se à construção da própria vida a partir de maneiras determinadas pelos próprios sujeitos (Edgardo CASTRO, 2009).

Para o processo de feminilização, a ingestão de hormônios caracteriza-se como ato indispensável e fundamental na fabricação desse corpo. "O corpo só se torna útil se é ao mesmo tempo corpo produtivo e corpo submisso" (FOUCAULT, 2009a, p. 29). Pode-se dizer que o corpo também assume uma posição de objeto, em que nele tudo se faz. Ou seja, a partir da reconstrução dos traços, dos gestos, das vestimentas; enfim, de toda uma estética corporal, ocorre um processo de modelagem.

Ao acompanhar Maria Regina em uma clínica médica para autorizar a realização de seus exames préoperatórios, ela afirma o quanto o corpo é local de intervenções, quando comenta sobre a cirurgia de implante

774 Estudos Feministas, Florianópolis, 24(3): 761-784, setembro-dezembro/2016 
${ }^{4}$ As bombadeiras, geralmente, são travestis e transexuais que aplicam silicone líquido e industrial nos corpos de outras travestis e transexuais

\footnotetext{
${ }^{5}$ Preciado (2008) define como farmaco os processos de governo biomolecular e porno os processos referentes ao governo semióticotécnico da subjetividade sexual, "dos quais a pílula anticoncepcional e a Playboy são paradigmáticos".
}

de prótese mamária realizada no de ano 2013. Ela relata como foi sua experiência com a colocação do silicone industrial.

[...] perguntei para Maria Regina como tinha sido sua experiência com a bombadeira, ${ }^{4}$ já que havia me contado que colocara silicone nas nádegas. Ela disse que foi tranquilo, que teve que ficar de repouso por alguns dias e que em um dia fez um lado e depois outro. Maria Regina comentou que dificilmente alguma travesti ou transexual não faz uso do silicone industrial. Na clínica médica, onde estava autorizando seu exame, Maria Regina mostrou-me seu encaminhamento para a realização dos exames a serem feitos antes da cirurgia e também o encaminhamento para a própria cirurgia de implante de silicone. [...] Nota-se que ela está muito contente com a sua cirurgia, realmente deve ser uma grande realização, pois, segundo ela, "é um corpo que está se construindo aos poucos de acordo com a sua alma" [EXCERTO DIÁRIO de CAMPO, 28/05/2013].

A ingestão de hormônios e o implante de silicone, seja industrial ou não, são, talvez, as mais significativas técnicas utilizadas para a produção do corpo na direção do feminino. A maquiagem, a produção do cabelo e o investimento no vestuário são as primeiras transformações apresentadas; entretanto, parece ser a mudança na biologia corporal que produz os efeitos mais significativos com relação à construção da travestilidade e da transexualidade. Sem dar a devida importância aos perigos que pode acarretar o silicone industrial, travestis e transexuais buscam maneiras mais acessíveis para contornar os seus corpos.

Sobre essa questão da farmacologia no processo de construção da subjetividade, Beatriz Preciado (2008) discute sobre os processos de governo dos corpos, fazendo um deslocamento do conceito de biopoder de Foucault para o conceito de farmacopoder ou farmacopornografia. ${ }^{5}$ Isto é, de uma sociedade do controle passa-se a uma sociedade farmacopornográfica, em que o controle é exercido do próprio sujeito sobre si mesmo.

A partir dos anos 40 , o biopoder toma a forma do regime farmacopornográfico, segundo a minha interpretação. [...] Assim sendo, para vigiar o corpo, as técnicas de controle miniaturizam-se depois da Segunda Guerra Mundial; com a invenção dos hormônios, as técnicas de controle tornam-se interiores. Já não é necessário o hospital, o quartel, a prisão, porque agora o próprio corpo foi convertido num território de vigilância, na ferramenta definitiva. O que 
está a acontecer quando se toma testosterona ou a pílula? Engole-se uma cadeia de signos culturais, uma metáfora política que comporta uma definição performativa de construção do gênero e da sexualidade. O género, feminino ou masculino, aparece com a invenção das moléculas (ENTREVISTA, 2013).

Segundo Preciado (2008), a pílula anticoncepcional possui muito mais que a função de controle da reprodução; ela também possui função importante na fabricação e controle dos gêneros. Ela tem a capacidade de operar sobre a biologia do corpo, produzindo efeitos nas subjetividades e, consequentemente, no gênero. Para ela, os hormônios são "metáforas tecno-vivas", isto é, "artefatos farmacopornográficos" capazes de produzir e transformar os corpos. A partir da ingestão de hormônios, portanto, a feminilidade pode ser fabricada.

Essas técnicas de produção corporal exteriorizam e visibilizam as particularidades das travestis e transexuais, ingressando-as no universo feminino, embora a feminilidade travesti evidencie, em muitos casos, um corpo híbrido entre o masculino e o feminino. O corpo é o suporte de investimentos. Ao tornar-se atrativo, torna-se, também, fonte de sustento. A prostituição é uma experiência que necessita do corpo carne e do corpo prazer.

\section{Travestilidades e transexualidades: prostituir-se...}

A prostituição nem sempre é caracterizada como uma atividade de exploração do corpo, como fonte de sustento. Embora ela tenha sido comumente associada ao universo das travestis e transexuais como uma experiência marginalizada, a prostituição não é somente um trabalho, mas, também, é um espaço de produção das feminilidades, de sociabilidades e de visibilidades.

[...] me lembro, a primeira vez que eu vi uma travesti no show de calouros, que eu disse: Eu quero ser assim, sabe? Eu tinha aquela ilusão, da mulher, porque a visão da mulher é uma coisa que me passa uma coisa de poder, de sensualidade enfim e eu sempre sonhei aquilo pra mim, sabendo que eu não era mulher, mas que eu poderia me tornar e, para tudo isso, eu precisei criar minha independência. Foi quando eu saí de casa, fui parar na prostituição. Eu não fui nem pelo modo de sobrevivência. Na verdade eu fui pelo glamour que eu achava que tinha a coisa. Pela vida social de travesti, de estar sempre vestida de mulher. Então, pelo simples fato de hoje eu poder colocar uma roupa feminina e poder ir onde eu quiser, entrar numa loja e comprar o que eu quiser, já pra mim é muito gratificante (Cindy).

776 Estudos Feministas, Florianópolis, 24(3): 761-784, setembro-dezembro/2016 
Quando eu comecei a me vestir de mulher, eu ia, achava tudo bonito. Eu achava as travestis que trabalhavam na esquina, as mais antigas, eu achava tudo bonito, achava um luxo, tinha aquela atração por aquilo ali. E quando eu vi que eu queria mudar meu corpo, que eu queria mudar a minha forma de viver a vida, era a única coisa que naquele momento eu tinha pra fazer. Eu vivi como profissional, trabalho mesmo, [...] eu fiquei acho que oito anos vivendo da prostituição e vivendo da noite, mas eu sempre soube que teria um final (Maria Regina).

De acordo com as enunciações, a construção da feminilidade de algumas transexuais e travestis é realizada a partir da ideia do corpo feminino como suporte de sensualidade e de poder; ou seja, a fantasia de que ser mulher requer investir incessantemente na beleza e na sensualidade foi um dos marcadores na construção da travestilidade de Cindy. O glamour é um aspecto muito presente na vida das travestis.

[...] ○ sucesso no processo de feminilização, o reconhecimento público de suas qualidades, sobretudo artísticas e criativas e a possibilidade de materializar isso em bens que remetem ao consumo do luxo. Ao mesmo tempo, o glamour tem sido um operador capaz de criar um contraponto entre as experiências de sucesso e aquelas da abjeção (PELÚCIO, 2011, p. 78).

A prostituição, também, é representada por um universo glamoroso que, além de constituir-se como um modo de adquirir recursos financeiros, também é uma experiência em que se pode tornar visível a criatividade acerca da produção de sua feminilidade. Esse entendimento está presente na narrativa que expressa a representação de que as travestis na esquina assumem por sua beleza e luxo. A prostituição, para muitas travestis, parece ser desejada, representando eficiência na construção da feminilidade.

É na convivência nos territórios de prostituição que as travestis incorporam os valores e formas do feminino, tomam conhecimento dos truques e técnicas do cotidiano da prostituição, conformam gostos e preferências (especialmente os sexuais) e muitas vezes ganham ou adotam um nome feminino. Este é um dos importantes espaços onde as travestis constroemse corporal, subjetiva e socialmente (Marcos BENEDETTI, 2013).

A prostituição é mesclada pela luta pela sobrevivência e a fabricação de si, tornando visível todo o aparato que constitui a feminilidade das travestis e transexuais e que, consequentemente, seja a partir da simples utilização de marcadores e vestimentas ditos do gênero feminino, ou a 
partir de um investimento mais específico, como a ingestão de hormônios, a realização de plástica facial, a aplicação de silicone, entre outros processos que fazem parte da tecnologia da transformação corporal. Nesse processo de transformação e construção da subjetividade, o corpo, além de ser ator, é também cenário dessa produção (BENEDETTI, 2013a).

A prostituição, para Cindy, é uma escolha. Nem toda travesti ou transexual passa pela experiência da batalha na rua, da prostituição.

A prostituição [...] acredito que tu vá ouvir isso de várias pessoas, é opção de vida, porque mal ou bem todas as pessoas que eu conheço, as travestis, minhas amigas, que eu conheço e que trabalham na noite, que são profissionais do sexo, todas mal ou bem nunca passaram fome. Todas mal ou bem tiveram a opção de estudar, mas não quiseram. Então, ah, eu precisei ir pra noite. Não, tu não precisou ir pra noite. Foi uma opção de escolha.

Para ela, a prostituição é uma atividade produtiva financeiramente e é exercida por quem realmente deseja vivenciar essa experiência, por vontade própria e não por obrigação. A prostituição é destacada, também, como a única saída pelas travestis e transexuais que são excluídas e rejeitadas no mercado de trabalho e também na família. O dinheiro é que acaba as atraindo para a prostituição, pois necessitam deste, tanto para sustentar-se e produzir-se, quanto para manter suas relações familiares e amorosas (KULICK, 2008).

Embora a prostituição seja caracterizada por muitas travestis e transexuais como a única alternativa de trabalho e de lucro financeiro, é imprescindível desconstruir a ideia de que toda travesti e transexual é profissional do sexo e que a construção de sua subjetividade seja determinada a partir dessa experiência, pois, para muitas delas, isso é caracterizado como um estigma, causando rejeição e exclusão social.

Mesmo que o espaço da prostituição seja um lugar de aprendizagens, de inserção ao universo feminino e de experiências prazerosas, nesse espaço, o preconceito também opera. Muitas travestis e transexuais trabalham prostituindo-se porque são excluídas de outros contextos; no entanto, nesse local também vivenciam situações perigosas e são expostas às inúmeras formas de violência:

As piores situações homofóbicas que eu vivenciei foi na quadra mesmo. Na noite, na pista. De levar ovada, de levar garrafada de carro passando, sabe? De pessoas que passavam de carro, geralmente eram

778 Estudos Feministas, Florianópolis, 24(3): 761-784, setembro-dezembro/2016 
homens, que se dizem homens e heterossexuais, né. De sair com alguém pra fazer um programa e a criatura te deixar lá no quinto dos infernos, onde tu não sabes nem onde é. Então, eu chegava e já acertava, dizia assim: - Olha, querido, eu cobro adiantado. E tinha os que diziam: - Não, não. Depois eu te pago. Eu: Não quero saber, tu vai me pagar agora. [...] uma ou duas vezes que eu tentei fazer isso, botaram a arma na minha cara e disseram: - Não, agora tu vai fazer o programa. Eu não vou te pagar e tu ainda vai ficar aqui. la fazer o quê? la levar um tiro, batendo boca, de graça (Cindy).

Quem trabalha na noite tem que saber se defender. $E$ se tu não sabe, tu aprende que o mundo é outro. As pessoas são diferentes. Muitas vezes tu não enxerga as pessoas que são noturnas, tu não enxerga elas durante o dia, são pessoas diferentes. Hoje eu enxergo, hoje eu trabalho, sou cabeleireira, trabalho no salão. Com certeza a vida é melhor hoje do que antes. $E$ agradeço a Deus por ter tido essa saída, porque muitas não têm. Muitas ficam pelo meio do caminho. Outras se perdem com drogas. Outras se perdem em roubo. Outras se envolvem com muita coisa ruim, que tu não tira coisa boa nisso. A única coisa boa é que tu consegue te manter e, através disso, da própria noite, que tu te transforma, então, na tua vitrine e tu tens que reformular ela todos os dias. A única coisa boa que eu tenho da noite, de tu ter conhecido a noite, foi o meu marido. Por isso tudo que eu te digo de coração: Valeu a pena! Se eu não tivesse ido por esse caminho, eu não teria conhecido ele (Maria Regina).

As enunciações evidenciam que algumas estratégias são necessárias para lidar com alguns sujeitos preconceituosos e situações desagradáveis. Maria Regina destaca um aspecto dessa experiência, ou seja, além do sustento que ela adquiriu com essa vivência, narra sua satisfação ao ter conhecido o seu marido nesse espaço. Para ela, o dinheiro era importante para sua "transformação", para sua modelagem estética e corporal. Como ela menciona, tratavase de uma vitrine exposta diariamente, evidenciando a sua incessante produção para "vender" sua imagem no mercado sexual. Porém, o mais significativo dessa experiência foi conhecer o marido. O ambiente da prostituição "constitui-se também no principal espaço de trocas matrimoniais" (BENEDETTI, 2013). Ainda que, nos ambientes de prostituição, as experiências também sejam acompanhadas de violência e coloquem as profissionais do sexo em posição de vulnerabilidade, como relata Cindy, esse espaço permite às travestis e transexuais novas formas de viver, isto é, de (re)inventar suas subjetividades. 


\section{Transexualidades e travestilidades: (re)inventar-se}

Evidenciamos, a partir das enunciações das transexuais e da travesti, que se inscrevem no corpo as marcas da feminilidade que, a todo instante, é reforçada e produzida. $O$ corpo torna-se o sustentáculo dessa produção. Ele é "superfície de inscrição dos acontecimentos (enquanto que a linguagem os marca e as ideias os dissolvem), lugar de dissociação do Eu (que supõe a quimera de uma unidade substancial), volume em perpétua pulverização" (FOUCAULT, 2004, p. 22). É no corpo e por meio deste que se busca o reconhecimento e a afirmação de si. Os corpos das transexuais e travestis perturbam, incomodam, desestabilizam porque promovem fissuras na norma estabelecida socialmente.

Embora muitos atos sejam performativos, as inscrições corporais de travestis e transexuais são também entendidas como subversivas, e, essas, portanto, tornam-se indicadores de classificação, hierarquização, ordenação, normalização. É a partir da criação dessas outras possibilidades, da construção de outros modos de ser, que os sujeitos constituemse e (re)inventam-se.

No texto, buscamos evidenciar esses distintos modos de existir a partir das diferentes formas de ser travesti e transexual. As entrevistadas relataram diversos entendimentos acerca dessas subjetividades, demonstrando que não há uma única forma de ser. Nesse sentido,

[...] o 'universo trans' está composto por esta miríade de sujeitos, identidades, corpos, práticas e significados que voluntariamente, (trans)formam-se e constroemse em função de valores e concepções do gênero que são diferentes daqueles hegemônicos na sociedade abrangente (BENEDETTI, 2013a).

Ao caracterizarem a travestilidade e a transexualidade, as entrevistadas apontam elementos constitutivos de suas subjetividades, que reproduzem algumas convenções sociais, mas também apresentam outras experiências, outras feminilidades e outras relações consigo mesmas. Evidenciamos que elas se utilizam de técnicas de alteração corporal, muitas vezes nocivas para suas vidas, na tentativa de adequar seus corpos às prerrogativas de gênero heteronormativas. Assim, elas explicitam que ser mulher é ser passiva e penetrada; ser mulher é ter seios, quadris, vagina e, para isso, desafiam as normativas estabelecidas a seus corpos biológica e culturalmente definidos como pertencentes ao sexo biológico masculino. Embora, nesse aspecto, de alguma forma, sejam dissidentes da heteronormatividade, em alguns momentos, mantêm-se normatizadas quando afirmam ter marido, realizar 
${ }^{6}$ Segundo Foucault (1997, p. 109), as técnicas de si "são procedimentos, que, sem dúvida, existem em toda civilização, pressupostos ou prescritos aos indivíduos para fixar sua identidade, mantê-la ou transformá-la em função de determinados fins, e isso graças a relações de domínio de si, sobre si ou de conhecimento de si por si". afazeres domésticos, ter seios, "parecerem-se com uma mulher pois se sentem mulher", reproduzindo aquilo que a sociedade institui e afirma ser de mulher.

A partir de técnicas de si, ${ }^{6}$ as transexuais e travestis trazem à tona diferentes posições de sujeito, ou seja, por meio de inúmeras tecnologias de transformação corporal, elas produzem seus corpos, projetam suas vidas e evidenciam outras possibilidades de viver os gêneros e as sexualidades, desafiando, em muitos casos, a heteronormatividade.

O processo de constituição de si é contínuo, transitório e de (re)construção permanente. É atravessado por resistências, pela emergência de singularidades, as quais nos possibilitam repensar a normalidade e anormalidade, e pela criação de diferentes modos de existência.

\section{Referências}

ALBERTI, Verena. Manual da história oral. 3.ed. Rio de Janeiro: FGV, 2005

BEAUVOIR, Simone. O segundo sexo, v. 2. São Paulo: Difusão Europeia do Livro, 1967.

BENEDETTI, Marcos. A batalha e o corpo: breves reflexões sobre travestis e prostituição, 2013. Disponível em: http:/ /www.ciudadaniasexual.org/boletin/b1 1/breves reflexoes _sobre_travestis_e_prostituicao.pdf. Acesso em: 27 jun. 2013. - (Trans)formação do corpo e feitura do gênero entre travestis de Porto Alegre, Brasil. Disponível em: http:// pt.scribd.com/doc/122336082/Artigo-Irans-formacao-docorpo-e-feitura-do-genero-Marcos-Benedetti. Acesso em: 3 jul. $2013 a$.

BENTO, Berenice. O que é transexualidade. São Paulo: Brasiliense, 2008.

A reinvenção do corpo: sexualidade e gênero na experiência transexual. Rio de Janeiro: Garamond, 2006.

BENTO, Berenice; PELÚCIO, Larissa. "Despatologização do gênero: a politização das identidades abjetas". Revista Estudos Feministas, v. 20, n. 2, p. 569-581, maio/ago. 2012.

BUTLER, Judith. "Desdiagnosticando o gênero". Physis Revista de Saúde Coletiva, Rio de Janeiro, v. 19, n. 1, p. 95-126, 2009. Disponível em: http://www.scielo.br/pdf/physis/ v19n1/v19n1a06.pdf. Acesso em: 12 jul. 2013.

. Problemas de gênero: feminismo e subversão da identidade. 3.ed. Rio de Janeiro: Civilização Brasileira, 2010.

"Corpos que pesam: sobre os limites discursivos do 'sexo'”. In: LOURO, Guacira Lopes et al. (Orgs.). O corpo educado. Belo Horizonte: Autêntica, 2007. p. 151-172. 
CAETANO, Márcio Rodrigo Vale. Gênero e sexualidade: um encontro político com as epistemologias de vida e os movimentos curriculares. 2011. Tese (Doutorado em Educação) - Programa de Pós-Graduação em Educação, Universidade Federal Fluminense, Rio de Janeiro.

CASTRO, Edgardo. Vocabulário de Foucault: um percurso pelos seus temas, conceitos e autores. Belo Horizonte: Autêntica, 2009.

DELORY-MOMBERGER, Christine. Biografia e educação: figuras do indivíduo-projeto. Natal: EDUFRN; São Paulo: Paulus, 2008.

DREYFUS, Hubert; RABINOW, Paul. Michel Foucault: uma trajetória filosófica: para além do estruturalismo e da hermenêutica. 2.ed. Rio de Janeiro: Forense Universitária, 2010.

ENTREVISTA: Preciado \& Butler [parte l]. "Primeira parte: o novo sujeito da revolução", 28/10/2013. Revista Têtu, Paris, n. 138, nov. 2008. Disponível em: http://lusoqueer.blogspot. com.br/2013/10/preciado-butler-parte-i.html. Acesso em: 10 out. 2015.

FILHO, Kleber Prado; TRISOTTO, Sabrina. "A psicologia como disciplina da norma nos escritos de M. Foucault". Revista Aulas, Campinas: UNICAMP, Dossiê Foucault, v. 3, n. 1, p. 1-14, fev. 2007. Disponível em: http://www.unicamp.br/ aulas/pdf3/KLEBER.pdf. Acesso em: 7 out. 2015.

FONSECA, Márcio Alves. Michel Foucault e a constituição do sujeito. São Paulo: EDUC, 2003.

FOUCAULT, Michel. Arte, epistemologia, filosofia e história da medicina. Rio de Janeiro: Forense Universitária, 2011. (Ditos e Escritos VII)

. A história da loucura na Idade Clássica. 9.ed. São Paulo: Perspectiva, 2010.

. Ética, sexualidade, política (Ditos e Escritos V). 2.ed. Rio de Janeiro: Forense

Universitária, $2010 a$. A ordem do discurso. São Paulo: Loyola, 2009.

Vigiar e punir: nascimento da prisão. 36.ed. Petrópolis: Vozes, 2009a.

Arqueologia do saber. 7.ed. Rio de Janeiro: Forense Universitária, 2005.

. Microfísica do poder. 20.ed. Rio de Janeiro: Graal, 2004.

Ditos e escritos I: problematização do sujeito: psicologia, psiquiatria e psicanálise. 2.ed. Rio de Janeiro: Forense Universitária, 2002.

"Segurança, território e população (1977-1978)". In: . Resumo do Collège de France (1970-1982). Rio de Janeiro: Jorge Zahar, 1997. p. 79-86.

KULICK, Don. Travesti: prostituição, sexo, gênero e cultura no Brasil. Rio de Janeiro: Fiocruz, 2008. 
LOURO, Guacira Lopes. Um corpo estranho: ensaios sobre sexualidade e teoria queer. Belo Horizonte: Autêntica, 2004.

PELÚCIO, Larissa. "Próteses, desejos e glamour: tecnologias de si na construção de corpos travestis no mercado do sexo transnacional". In: SANTOS, Luís Henrique Sacchi dos; RIBEIRO, Paula Regina Costa (Orgs.) Corpo, gênero e sexualidade: instâncias e práticas de produção nas políticas da própria vida. Rio Grande: FURG, 2011. p. 7786.

"Travestis, a (re)construção do feminino: gênero, corpo e sexualidade em um espaço ambíguo". Revista ANTHROPOLÓGICAS, ano 8, v. 15, n. 1, p. 123-154, 2004. Disponível em: http://www.revista.ufpe.br/revistaanthro pologicas/index.php/revista/article/view/34/34. Acesso em: 10 jul. 2013.

PERES, Wiliam Siqueira. Travestis, cuidado de si e serviços de saúde: algumas reflexões, 2013. Disponível em: http:// www.defensoria.sp.gov.br/dpesp/Repositorio/39/ Documentos/travestis_cuidado_de_si_e_servicos_de_saude. pdf. Acesso em: 30 mai. $201 \overline{3}$.

"Travestilidades nômades: a explosão dos binarismos e a emergência queering". Revista Estudos Feministas, v. 20, n. 2, p. 539-547, mai/ago. 2012.

"Travestis: corpos nômades, sexualidades múltiplas e direitos políticos". In: SOUZA, Luiz Antônio Francisco de; SABATINE, Thiago Teixeira; MAGALHÃES, Boris Ribeiro de (Orgs.). Michel Foucault: sexualidade, corpo e direito. Marília: Oficina Universitária; São Paulo: Cultura Acadêmica, 2011. p. 69-104.

"Cenas de exclusões anunciadas: travestis, transexuais, transgêneros e a escola brasileira". In: JUNQUEIRA, Rogério Diniz (Org.). Diversidade Sexual na Educação: problematizações sobre a homofobia nas escolas. Brasília: Ministério da Educação, Secretaria de Educação Continuada, Alfabetização e Diversidade, 2009. p. 235-264.

PRECIADO, Beatriz. Texto Younqui. Madrid: Editorial Espasa Calpe, 2008.

PRINS, Baukje; MEIJER, Irene Costera. "Como os corpos se tornam matéria: entrevista com Judith Butler". Revista Estudos Feministas, v. 10, n. 1, p. 155-167, jan. 2002.

SALIH, Sara. Judith Butler e a Teoria Queer. Belo Horizonte: Autêntica, 2012.

VIANNA, Heraldo Marelim. Pesquisa em educação: a observação. Brasília: Liber Livro, 2007.

[Recebido em 26/09/2013, reapresentado em 29/10/2015 e aceito para publicação em 03/05/2016] 
Transvestites and Transsexuals: (Trans)Formed Bodies and Production of Femininity Abstract: In this article, we discuss the body production of transvestites and transsexuals, questioning the effects on their subjectivation processes. Therefore, we analyzed statements produced from the methodology of Thematic Oral History and Participant Observation. In the constitution process of travestilities and transsexualities, investing in the manufacturing of a female body is a way of making it visible and attractive. Prostitution is highlighted as an experience that produces effects in the construction of femininity and self-manufacturing. From techniques of the self, transsexuals and transvestites bring up different subject positions, showing other possibilities of living genders and sexualities, challenging, in many cases, heteronormativity.

Key words: Bodies; Transvestites; Transsexuals; Femininity; Self-(Re)Invention.

784 Estudos Feministas, Florianópolis, 24(3): 761-784, setembro-dezembro/2016 